the patient and an excellent learning experience for the trainee. My occasional glimpses of intimidating ward rounds since as an observer have done nothing to convince me that Sidney Benjamin's format has been bettered.

Teresa J. Black, consultant psychiatrist, Black Country Partnership NHS Foundation Trust, Wolverhampton, UK, email: Teresa.Black@bcpft.nhs.uk

1 Bulletin comment: In praise of the psychiatric ward round. BJPsych Bull 2015; 39: 260 .

doi: $10.1192 / \mathrm{pb} .39 .6 .316 \mathrm{~b}$

\section{The GMC review of fitness to practise investigations and its impact on doctors}

The fact that doctors have a higher suicide rate than the general population is of great concern. ${ }^{1}$ Given the death of several doctors while under the General Medical Council (GMC) fitness to practise procedures, the internal review and report on this matter is very welcome. ${ }^{2}$ Contact with the GMC can result in significant anxiety for doctors.

What did the report reveal? The imbalance in resources for support in areas without access to services such as the Practitioner Health Programme (PHP) and Mednet was noted, and the suggestion of a national support service to provide doctors with confidential treatment is welcome. However, funding this service by increasing GMC fees could be perceived as a conflict of interest. Offers of support from the GMC are likely to be viewed at best in an ambivalent or distrustful light. Indeed, despite being run by the British Medical Association (BMA), doctors were concerned about revealing information to a $\mathrm{GMC}$-funded helpline. ${ }^{2}$ Doctors under investigation are likely to be even more reluctant to discuss issues with someone from the GMC as they may perceive that any information shared could have an impact on the investigation, potentially resulting in them struggling to access the support that they desperately need and a lack of engagement. In this respect, a PHP-like service has the advantage of being considered confidential and accessible. It was disappointing that the report mentioned neither the Royal College of Psychiatrists nor their Psychiatrists' Support Service (www.rcpsych.ac.uk/pss), established in 2007 to allow psychiatrists to talk, via telephone, to another psychiatrist and receive advice and signposting, a unique provision among medical Royal Colleges.
Doctors undergoing investigation often feel a sense of accusation and blame. Indeed, in 2007 the GMC changed the burden of proof requirement to follow the civil standard, 'on the balance of probabilities', rather than the criminal standard, 'beyond all reasonable doubt', which may well lead to doctors feeling 'guilty until proven innocent'. ${ }^{3}$ The suggestion that doctors consider themselves 'innocent until proven guilty' is welcome; however, the report offers no suggestions as to how this could be achieved. It is worrying that the report did not mention any actions taken by the GMC in the six instances where doctors were known to be at risk of suicide. There was no indication that risk assessments were performed for these doctors, when psychiatric input was likely to have been beneficial. As most health referrals have a mental health component, it is vital to consider that doctors undergoing investigation may be unwell and the benefits of psychiatric expertise should be recognised. We echo the Faculty of Occupational Medicine's disappointment that the report failed to reference existing competencies for treating doctors effectively. 4

Declaration of interest: All authors are doctor advisors for the Psychiatrists' Support Service, Royal College of Psychiatrists. This article represents our personal view and not that of the College.

Elena Baker-Glenn, ST6 in general adult and old age psychiatry, Cambridgeshire and Peterborough NHS Foundation Trust, Cambridge, UK, email: elenabakerglenn@yahoo.co.uk, Jane Marshall, consultant psychiatrist, South London and Maudsley NHS Foundation Trust, London, UK and Ricky Caplan, honorary consultant psychiatrist, Greater Glasgow and Clyde Health Board, Glasgow, UK.

1 Meltzer H, Griffiths C, Brock A, Rooney C, Jenkins R. Patterns of suicide by occupation in England and Wales: 2001-2005. Br J Psychiatry 2008; 193: $73-6$.

2 Horsfall S. Doctors Who Commit Suicide while Under GMC Fitness to Practise Investigation. General Medical Council, 2014.

3 Dyer C. GMC approves change in the standard of proof. BMJ 2007; 335 1230-1.

4 Faculty of Occupational Medicine of the Royal College of Physicians. FOM response to GMC-commissioned report into doctors who commit suicide while under GMC fitness to practise investigations. Royal College of Physicians, 2014. Available at: http://www.fom.ac.uk/ press-releases/fom-response-to-gmc-commissioned-report-intodoctors-who-commit-suicide-while-under-gmc-fitness-to-practiseinvestigations.

doi: 10.1192/pb.39.6.317 